\title{
Alternative denominators in transport crime rates
}

\author{
Reka Solymosi $^{\mathrm{a}}$, Matt Ashby ${ }^{\mathrm{b}}$, Tom Cohen $^{\mathrm{c}}$, Aiden Sidebottom $^{\mathrm{d}}$ \\ ${ }^{a}$ Room 4.53 Williamson Building, School of Law, University of Manchester, Oxford Road, Manchester, M13 9PL \\ reka.solymosi@manchester.ac.uk \\ ${ }^{b}$ School of Social Sciences, Nottingham Trent University \\ ${ }^{c}$ Centre for Transport Studies, University College London \\ ${ }^{d}$ Department of Security and Crime Science, University College London
}

\begin{abstract}
Ensuring passenger security on mass transit is vital for modern cities. Failure to do so may jeopardize the societal, environmental and health benefits of public transportation. One challenge with securing transit environments comes from the difficulty of accurately estimating the risk of criminal victimization at various nodes, particularly with respect to the choice of denominator that most reliably captures variations in the number of opportunities for different crime types. In this paper, we draw on open-source data as denominators for calculating the risk of violent crime on London Underground. We argue that denominator choice can depend on the ease of availability, accuracy and applicability of the data required, and demonstrate how the choice of denominator significantly affects estimations of crime risk. We make recommendations for research, policy and practice in denominator choice, and finally integrate the results to develop a taxonomy of London Underground stations based on their risk profiles across all measures.
\end{abstract}

\section{JOURNAL ARTICLE PRE PRINT}

This is the version of this article submitted to a journal for publication. It has not yet been peer reviewed. It may vary from the final published version.

\section{Introduction}

Public transport is vital to modern cities. It provides mobility for those without their own vehicles and reduces the societal and environmental costs of motor-vehicle use. The security of public transport systems is essential for two reasons. Firstly, transport systems are part of our critical infrastructure (Department for Homeland Security, 2015) and without them many cities quickly experience serious and costly disruption (Rodríguez-Núñez and García-Palomares, 2014). Secondly, any actual or perceived lack of security may act as a barrier to citizens' using public transport, reducing the societal benefit derived from the system (Peck, 2010).

Agencies with responsibility for public safety (such as police) and transport operators have an interest in maintaining system security. To do so, they must have a clear understanding of the type, level and 
distribution of any security threats (Smith and Clarke, 2000$)$. Since risk is invariably unevenly distributed in any given network (Braga et al. 2014), practitioners must be able to identify accurately which parts of a transport system are most at risk.

One way to estimate risk is to calculate crime incidence rates. An incidence rate is a measure of frequency taking account of the varying frequency of opportunities for crime (Skogan, 1976), giving a more-accurate representation of the risk to individuals (passengers, transport staff) than a 'raw' count of crimes. Incidence rates take the form $c / o$, where $c$ is the number of crimes of a particular type and $o$ is the number of opportunities for crimes of that type to occur (perhaps translated into easily comprehensible units by use of a multiplier, such as the number of crimes per 1,000 individuals).

The routine activities approach pioneered by Cohen and Felson (1979) defines an opportunity for a crime to occur as any occasion on which a motivated offender and a suitable target meet in the same place at the same time, in the absence of people (referred to as controllers) able to prevent that crime from happening (for a recent summary of this theoretical approach, see Eck and Madensen, 2015). Substantial research has demonstrated the utility of this approach as a basis for crime analysis and crime prevention (Eck, 2002). However, it has often been difficult to measure directly the theory's core concepts (Groff, 2007), with researchers instead relying on proxy measures. This is particularly the case where it is necessary to estimate the number of opportunities to calculate crime rates.

This articles discusses the strengths and weaknesses of various opportunity measures for making such calculations. Using open data on passengers and violent crime at London Underground stations, significant variation is demonstrated in which stations emerge as 'high risk' depending on which measure (denominator) is used. Additionally, an existing taxonomy of crime risk at places is tested in the context of transport crime using clustering techniques.

\section{The denominator dilemma}

The accuracy of a crime rate as a representation of risk depends on the denominator (representation of opportunity) that is chosen. Identifying denominators can be difficult: there is often a trade-off between how faithfully the data approximate the opportunity structure for the crime of interest and the practicalities of collecting such data. Ratcliffe (2010, p 12) referred to this as the "denominator dilmma".

Issues with denominator choice arise in all areas of transport research where rates must be calculated. An obvious example is the area of road safety, where the number of collisions, injuries or fatalities is divided by a suitable measure of exposure to produce a rate which enables inter-modal, spatial, temporal or other 
comparisons (Williams, 2003). The relative safety of cycling is a case in point: very different impressions of the risk associated with cycling arise, depending on whether the exposure measure used is distance travelled, time spent travelling, or trips made. The apparent relative safety of different modes consequently varies considerably depending on the exposure used (Teschke et al. 2013 ).

There exists in the literature a long-standing discussion of denominator choice for crimes in non-transport settings, which can be adapted to consider transport security issues. Perhaps the most common denominator is the residential population of the area under study. Further denominators include (for rape) the number of women living in an area (Boggs, 1965), (for burglary) the number of households (Rengert, 1981) and (for vehicle theft) the number of vehicles (Stipak, 1988). Pettiway (1985) took a different approach, modelling multiple variables to create a denominator index.

Evidently there are many choices. Harries (1981, p 148) warned that "uncritical application of population as a denominator ... may yield patterns that are at best misleading and at worst bizarre", a point earlier made by Lottier (1938). Boggs (1965), Harries (1981) and Skogan (1976) all demonstrated the importance of selecting a denominator that represents risk for a particular type of crime as accurately as possible. They also demonstrated that choosing the wrong denominator can easily lead to drawing erroneous conclusions about crime risk. Contrary to these findings, however, Cohen et al. (1985) found that calculating rates of burglary and vehicle theft using opportunity-based rates made little difference to their analysis when compared to population-based rates.

Recent studies in this area have applied newly available datasets that attempt to better approximate opportunities. Lemieux and Felson (2012) used National Crime Victimization Survey and American Time Use Survey data to estimate crime risk by place and type of facility; Chainey and Desyllas (2010) used purposecollected pedestrian modelling data. Andresen (2010), Andresen et al. (2012) and Kurland et al. (2014) all used processed satellite data to estimate the 'ambient' population in an area for use as a denominator. Malleson and Andresen (2015) used crowd-sourced data from Twitter to create estimates of the population at risk of mobile crimes (such as street robbery) at higher spatial and temporal resolutions than other available data, creating potentially better risk representations. However, none of these have been applied to transport crime.

Another element of place-based crime research applicable to transport settings that considers the role of place in crime risk is the classification of "crime places". Brantingham and Brantingham (1981), Brantingham and Brantingham (1995) and Clarke and Eck 2003) successively developed four types of crime places. The first is the crime generator, a place in which large numbers of people gather for purposes unrelated to crime 
and by doing so create a large number of crime opportunities. Such places tend to have a relatively high count of crime, since there are so many opportunities, but a relatively low crime rate. In the second type of place, known as a crime attractor, offenders are drawn to the area specifically for the criminal opportunities that it is known to offer. Such places - which include drug markets and red-light districts (Association of Chief Police Officers, 2008) - in general have both high counts of crime and high crime rates.

The third type - the crime enabler - describes places where there are particularly few people capable of stopping crimes occurring. While there may be a relatively low count of crimes in such places (because there is nothing about them that presents large numbers of opportunities) they tend to have high crime rates because there is little to stop what opportunities exist from being realised. The final type are crime-neutral places - Kinney et al. (2008, p 63) used the term "crime detractors" - characterised by low counts and low rates of crime.

By using these typologies, researchers and practitioners can develop effective responses to problematic stations, and roll out interventions aimed at similar events together. Using various open-data denominators we can explore how variation in crime rate interacts with these typologies above, and help practitioners and researchers identify to which group a station belongs, to inform effective crime prevention initiatives.

\section{Potential denominators for transport crime}

Public transport presents unique challenges for calculating crime rates. Railways and bus stations have no official resident population, and counting the actual number of people in a particular part of the system can be challenging.

Comparisons between networks can use system-wide measures of risk, such as crimes per revenue-mile or per passenger journey (Rodier and Issac, 2016). However, system-wide measures cannot be used to understand variations in risk within a system. Calculating local risk requires measures of exposure for each unit of comparison within the system.

The best denominator for calculating crime rates is that which most-accurately represents the opportunities for crime to occur. For example, opportunities (as defined in the routine activities approach) for violent crime occur when a person willing to do violence to another comes into contact with a person who the first is able to attack, in the absence of anyone capable of stopping them. However, there is unlikely to be any practical way of measuring the occurrence of such opportunities at different places on public transport. To do so would require understanding the motivations and capabilities of every traveller.

Since measuring opportunities directly is not possible, it is necessary to find a suitable proxy measure. 
Which proxy to use depends on two factors. The first is the accuracy with which a particular denominator represents the opportunities for crime in a particular place. As can be seen in the research on non-transport crime, some denominators are more-accurate representations of opportunity than others. The second factor is the availability of data for calculating a particular denominator. Different system operators will collect different data that might be useful in this regard - if a particular dataset is not available, it cannot be used, however accurately it would represent opportunity. In the transport environment the ideal denominator for calculating crime rates may well not be available because transport data are typically collected to facilitate administration of the system - such as understanding passenger flows and associated revenue - rather than for understanding or preventing crime.

To explore the impact of these issues, this study compared rates of violent crime on a large metro railway system calculated using six denominators representing different combinations of these two key factors (accuracy and availability).

The first two measures assume the organisation responsible for responding to transport crime in an area has no reliable local data on either the services making up the system or the passengers using them. Such a scenario may arise, for example, in the case of a police force responding to crimes on informal para-transit services provided mostly by unregulated owner-drivers (for a discussion of such services in the developing world, see Cervero and Golub, 2007).

In such circumstances, risk analysts may fall back on population-based denominators derived from government statistics. The standard measure of local population is the number of people ordinarily resident or resident on the day of the local census. In the United Kingdom (UK), the Office for National Statistics (ONS) has recently published an additional measure of the 'workday population' of each area (Office for National Statistics, 2013). This is the sum of the number of people working in an area and the number of non-working residents (including children and the retired). This does not measure people who may be in an area during the workday for other purposes (e.g. shopping or leisure activities), but may provide a better estimate of daytime population than the standard residential population measure. Both population measures were used in the present study.

Although widely available, residential population data are unlikely to be representative of crime opportunities on public transport. Not all local people will use a particular transport network and people who do not reside locally may well travel on the system. Workday population may provide a better indication of opportunities for crime in some areas. However, not all censuses or similar surveys capture information about people's workplaces, so this measure will not always be available. 
The second two denominators assume the transport operator has information about the features of the system but no reliable, local information about flows of passengers. This may be the case where a city operates a bus network but lacks the resources to conduct surveys or counts of passengers. This may particularly be the case if operators cannot use fare-revenue data to estimate passenger flow, for example on fare-free systems (Perone, 2002).

Two infrastructure-based denominators were compared here. The first is the number of transit lines passing through a particular location. This might be the best-available denominator in cases where an agency knows that a certain route served a particular point but does not know the service frequency (perhaps because the route is informal or the frequency variable). The second denominator in this category was the number of vehicles passing through each location during a representative time period, but without reference to the vehicles' combined capacity or ridership.

Infrastructure-based denominators have a potential advantage over population-based denominators in that they relate to features of the transport system, and so may be less affected by external factors that do not affect the number of opportunities for crime on the transport network. However, they are limited in that knowing about the infrastructure provides only limited information about the people on that infrastructure. For example, trains passing through a station may be almost empty or very full, but this cannot be determined by counting the number of trains. It may be assumed that trains are provided to meet demand, but that will not always be the case. For example, network infrastructure may not always allow vehicles to be turned around at the end of a busy section, meaning intensive service is provided at adjacent points even though there is little demand. It is plainly not the case that all services will be equally busy, but this may be a necessary working assumption in the absence of better information about passenger loading.

The final pair of denominators was derived from measures of the number of passengers using each station on the metro system. This reflects the information available on systems that record detailed passenger data. The first measure is the number of passengers entering or leaving each station. This can be measured directly at stations with ticket gates, or estimated from ticket-sales data (for a discussion of the accuracy of such estimates, see Steer Davies Gleave, 2017).

This measure has the potential to underestimate opportunities for crime at stations that are major interchanges but where relatively few passengers start or finish their journeys, such as Clapham Junction railway station in London or bus interchanges in the New Territories of Hong Kong. To deal with this potential issue, the final denominator tested in this study is the number of passengers travelling through a station, whether by entering, leaving or changing between trains. Data on interchanging passengers were 
available for this study because the city that provided data happens to collect it (as will be described below). However, this information cannot be easily derived from ticket data because passengers can often take multiple routes through a system, so it may not be available for all systems even if they have a relatively sophisticated understanding of passenger flows. Of the denominators described here, the passengerbased denominators are the closest to representing opportunities for crime. However, they are still limited: counting passengers tells you nothing about their motivation to commit violent crime or their vulnerability to victimisation.

\section{Data}

The aim of this paper is to assess the extent to which using different denominators affects the conclusions drawn about crime rates on a transport network. To compare different denominators, data from London Underground (LU) were used. LU is a large metro railway with 270 stations operating 10.8 billion seatkilometres and 1.3 billion passenger journeys per year (Transport for London, 2015b), making it one of the busiest railways in the world.

LU was chosen for this study because its operator, Transport for London (TfL), publishes detailed open data on ridership, allowing comparison of different denominators. This was combined with open crime data published by the Home Office on the www.police.uk platform. Open data sources - i.e. data that can be used freely by anyone for any purpose (Open Knowledge Foundation, 2017) - are valuable for crime analysis because they allow scholars to investigate research questions without the lengthy data-release negotiations that have typically characterised criminological research (Tompson et al., 2014). This facilitates faster research, which can increase the chance of results being produced in time for them to contribute to topical policy debates and/or inform practice.

One limitation of open crime datasets is that the locations of offences are often obfuscated to protect the privacy of the victim, for example by locating all crimes at the centre of the nearest street segment Ray et al., 2012). Privacy is less of a concern in relation to crimes on railways, because (unlike at a residential address) it is not possible to infer the identity of the victim from the location of the offence. For this reason, the locations of railway offences are not obfuscated in the police.uk data.

There is, however, another source of inaccuracy in determining the location of offences on transport systems. Since offences can occur on moving vehicles, the person reporting the crime to the police (usually the victim) will often not know the exact location at which the offence occurred (Newton et al., 2014a). For this reason, British Transport Police (BTP) - the police force responsible for policing LU - records 
Figure 1: Calculation of populations around LU stations from census output areas.

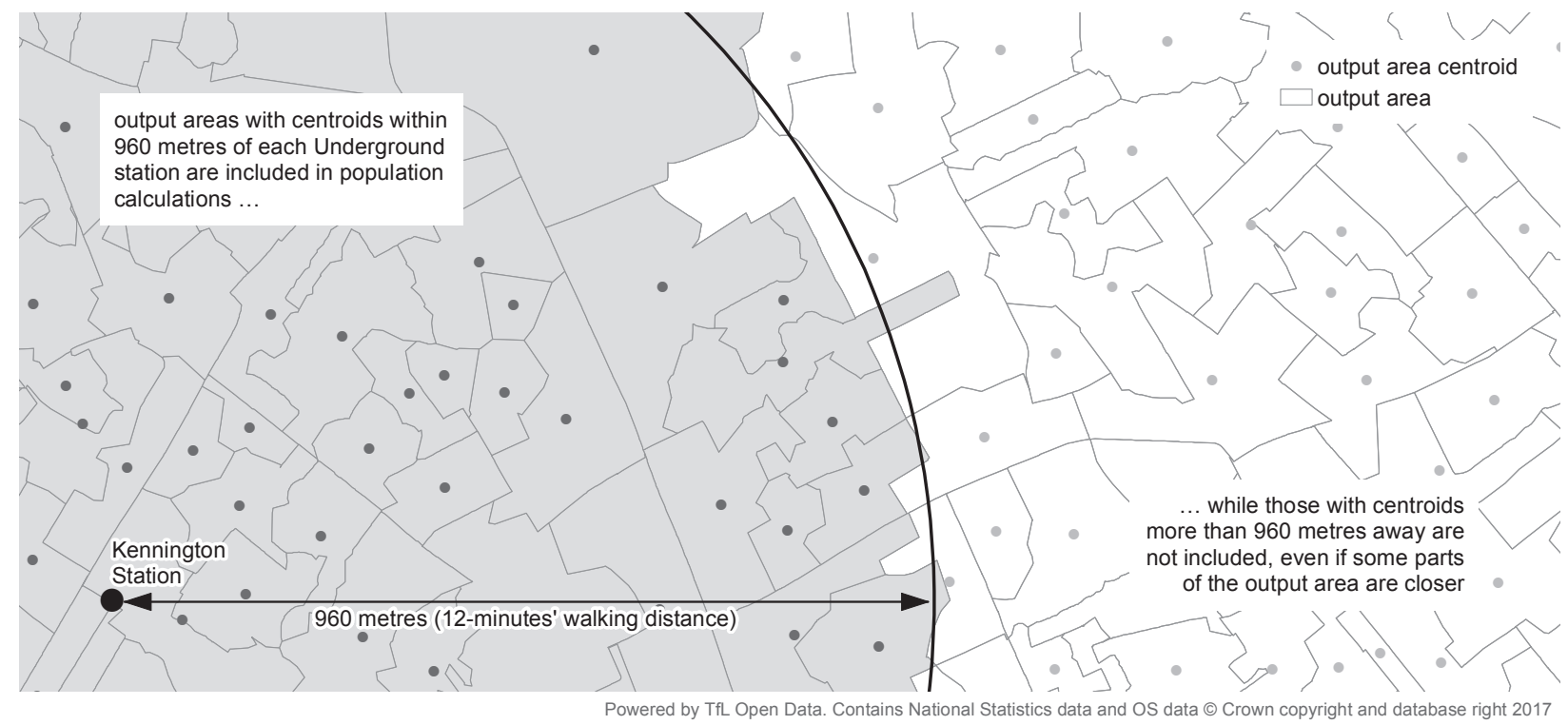

all crimes as having occurred at the nearest passenger station to which they are believed to have occurred (Ashby and Bowers, 2015). The available data were therefore counts of crimes of different types occurring at each LU station, although some of those offences are likely to have happened between stations (e.g. onboard moving trains). Counts of violent crime for the calendar year 2014 were extracted for analysis. This crime type was chosen because victims of violence are more likely to be able to report the offence location than are victims of property crimes such as pickpocketing, in which the victim often becomes aware of the offence only much later (Newton et al. 2014b). Choosing a single crime type also made the list of potential denominators manageable, since different crime types may require different denominators (Boggs, 1965). The violent crime data include all assaults, both with and without injury to the victim.

Data on residential and daytime populations were obtained from the 2011 UK census tables KS101EW and WD1101EW (Office for National Statistics, 2016). Census populations are published as counts of persons in small areas, known as output areas, calculated so that each contains an approximately equal number of people and is as socially homogeneous as possible (Office for National Statistics, 2017).

To calculate appropriate populations for each LU station, the populations of the surrounding areas were aggregated. TfL transport planning models assume that in order to access an LU station, a person will be prepared to walk for up to 12 minutes at a speed of 4.8 kilometres per hour, giving a maximum walking distance of 960 metres (Transport for London, 2015a). Consistent with these assumptions, populations for each station were calculated by drawing a buffer of radius 960 metres around each station and then taking 
the sum of the population of all the output areas the centroid of which fell within that buffer. Figure 1 illustrates this process. Since census data are available only for areal units, and people cannot always walk in a straight line to their destination in a city, the matching of population data to stations is inevitably imperfect.

Counts of lines and trains passing each station were obtained from LU timetables. Data on the number of passengers at each station were derived from the TfL Rolling Origin and Destination Survey (RODS). In this survey, a sample of LU passengers are asked to provide various information about their travel, including their origin and destination stations and the route between the two. These results are then adjusted using annual passenger counts to produce estimates of the number of passengers entering and exiting each station and, where necessary, changing between trains - on a nominal weekday in November (Transport for London, 2014).

\section{Methods}

Rates of violent crime were calculated for each LU station using each of the denominators described above. Stations were then ranked by the crime rate produced using each denominator, and the ranking of rates compared to the ranking of offences by crime count using Kendall's $\tau$. This correlation co-efficient was used because crime rates are typically skewed as a consequence of crime risk being concentrated in a small number of places (see Weisburd, 2015).

To determine whether the categorisation of crime places based on counts and rates described above could be applied to transport crime, a clustering algorithm was used. Partitioning Around Medoids (PAM) clustering (also known as $k$-medoids clustering) was used, as implemented in the $\mathrm{R}$ package cluster (Maechler et al. 2016, R Core Team, 2014). PAM was used rather than the more-common $k$-means algorithm because the latter is sensitive to outliers and the crime rates were expected to be skewed. Four clusters were specified, corresponding with the four categories - crime attractors, generators and enablers, and crime-neutral places - outlined by Clarke and Eck (2003).

\section{Results and discussion}

Figure 2 maps the number of violent crimes recorded by police as occurring at each LU station during 2014. Of the ten stations with the highest number of violent crimes, all are amongst the 20 busiest stations (Transport for London, 2017) and all but one (Stratford) are in the central business and leisure district. 
Figure 2: Number of violent crimes recorded by police as occurring at each London Underground station, 2014. The five stations with the highest counts are labelled.

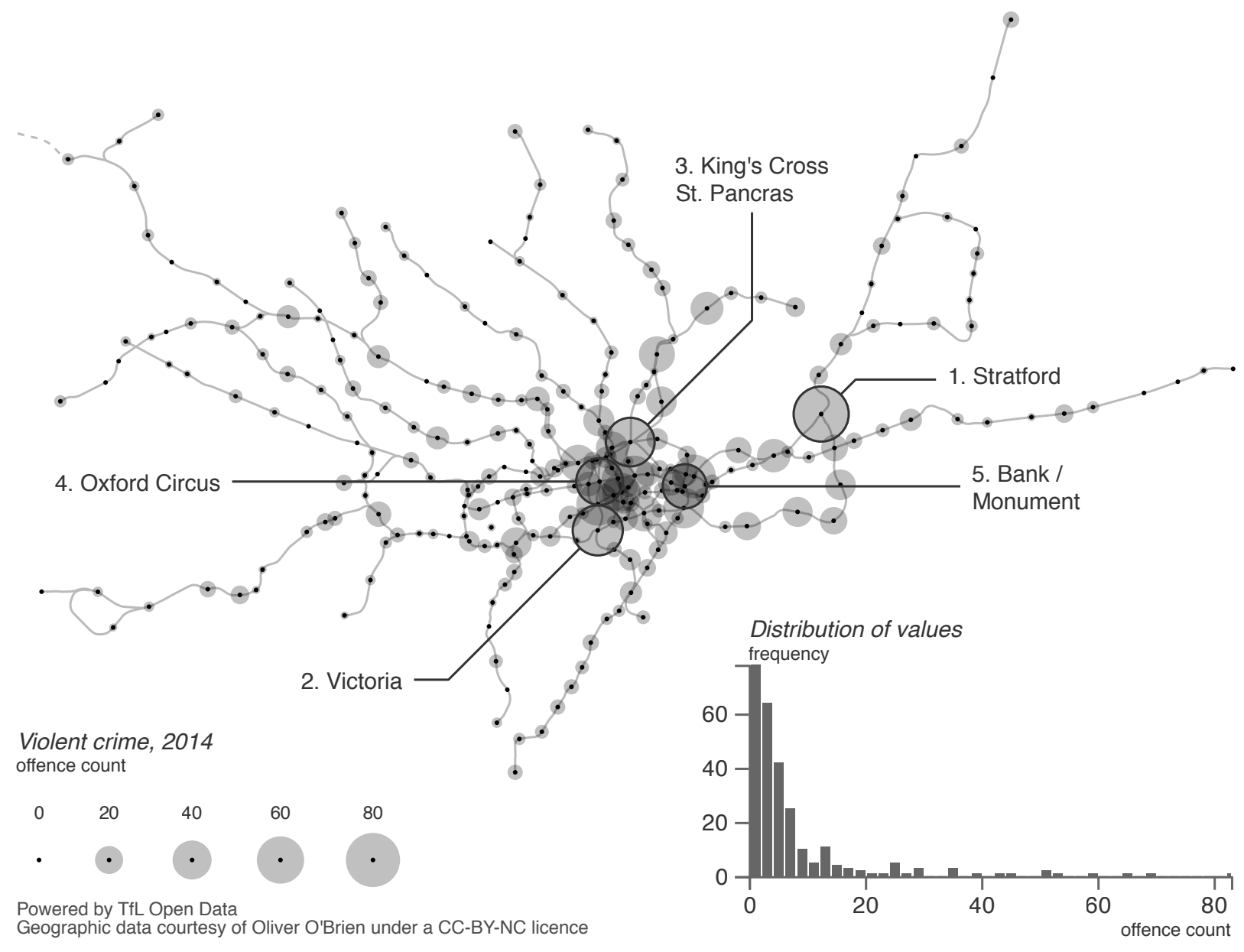

Counts of crimes may be a useful measure in certain circumstances, such as if a police commander wants to send officers to the stations where crimes were most likely to happen. However, the strong correlation between crime frequency and busy stations suggests that offence counts tell us little about the risk to individuals from violent crime. Figure 3 is a parallel co-ordinate plot showing the distribution of violent crime rates calculated using the different denominators. Each line represents a station and each vertical axis represents a different rate, ordered from left to right as the level of information about the system required to use that denominator increases. The purpose of this figure is to demonstrate the overall pattern of rates across all the stations on the LU system, so individual stations are not labelled with the exception of four that will be used as examples in the text below.

If all the denominators produced rates that ranked the stations in the same order of risk, none of the 
Figure 3: Distribution of violent crime rates for 2014 calculated using different denominators.

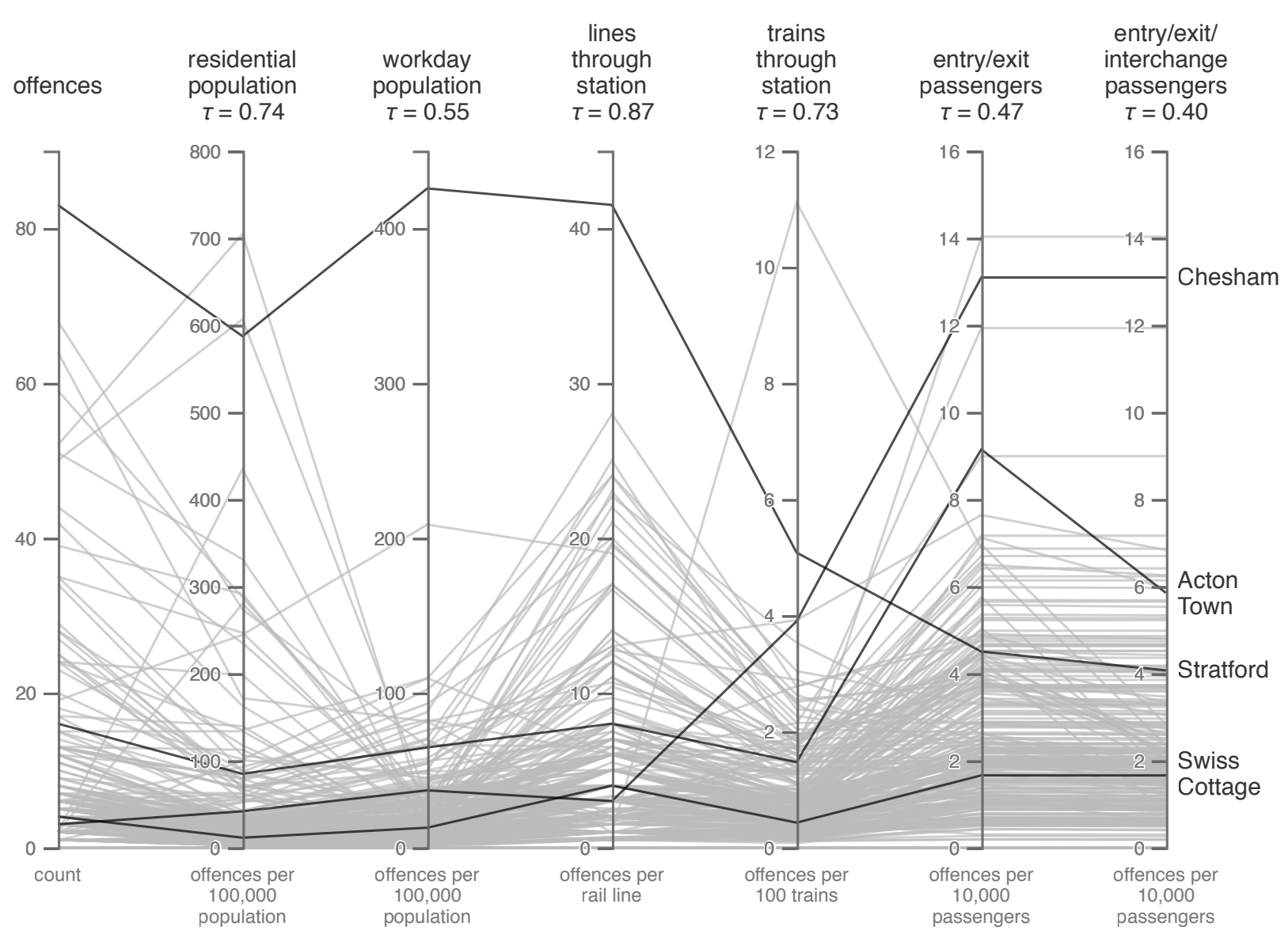

Powered by TfL Open Data

lines in Figure 3 would cross one another. Many lines cross between each pair of vertical axes, showing that the denominators order stations differently in terms of violent crime risk. Each vertical axis shows the bivariate Kendall's $\tau$ correlation between the rank orders of stations based on the count of offences at each station and the rate derived using that denominator. The lowest correlations with offence counts are for rates derived from passenger numbers.

Many stations - such as Swiss Cottage - have both a low count of violent crimes and a low rate, regardless of which denominator is used. For other stations, the choice of denominator has a substantial impact on the apparent risk from violent crime. Stratford - which recorded the highest number of violent crimes in 2014 - appears to be a high-risk station based on both residential and workday population, but presents only a moderate risk based on the number of passengers entering and exiting. The converse is true of Chesham the farthest LU station from Central London - which has a low rate of crime according to population-based 
Table 1: Stations with highest violent crime risk according to rates produced with different denominators.

\begin{tabular}{|c|c|c|c|c|c|}
\hline \multirow[b]{2}{*}{ Denominator } & \multicolumn{5}{|c|}{ Stations with highest violent crime risk } \\
\hline & 1 st & 2nd & $3 \mathrm{rd}$ & 4 th & 5 th \\
\hline Crime count & Stratford & Victoria & $\begin{array}{l}\text { King's Cross } \\
\text { St Pancras }\end{array}$ & Oxford Circus & $\begin{array}{l}\text { Bank/ } \\
\text { Monument }\end{array}$ \\
\hline \multicolumn{6}{|c|}{ Population-based denominators } \\
\hline Residential & $\begin{array}{l}\text { Bank/ } \\
\text { Monument }\end{array}$ & Green Park & Stratford & $\begin{array}{l}\text { Heathrow } \\
\text { Terminals } 123\end{array}$ & $\begin{array}{l}\text { Liverpool } \\
\text { Street }\end{array}$ \\
\hline Workday & Stratford & $\begin{array}{l}\text { North } \\
\text { Greenwich }\end{array}$ & West Ham & Canning Town & Canada Water \\
\hline \multicolumn{6}{|c|}{ Infrastructure-based denominators } \\
\hline Lines & Stratford & Seven Sisters & Camden Town & Canning Town & $\begin{array}{l}\text { Highbury and } \\
\text { Islington }\end{array}$ \\
\hline Trains & $\begin{array}{l}\text { Kensington } \\
\text { (Olympia) }\end{array}$ & Stratford & $\begin{array}{l}\text { Willesden } \\
\text { Junction }\end{array}$ & Chesham & Victoria \\
\hline \multicolumn{6}{|c|}{ Passenger-based denominators } \\
\hline Entry/exit & Roding Valley & Chesham & Chigwell & Acton Town & Sudbury Hill \\
\hline $\begin{array}{l}\text { Entry/exit/ } \\
\text { interchange }\end{array}$ & Roding Valley & Chesham & Chigwell & Sudbury Hill & Chiswick Park \\
\hline
\end{tabular}

measures but a high rate according to passenger-based measures.

Another way to demonstrate the differences in the rates produced by different denominators is to consider the common scenario of a transport operator wishing to focus attention at those stations where the risk from crime is greatest. Table 1 shows the five stations with the highest crime rates according to each denominator. These rankings demonstrate the influence of denominator choice on transport crime rates: none of the stations with the five highest rates according to the population-based denominators were in the top five according to passenger-based denominators.

Table1 1 also demonstrates the problems associated with some common denominators. The five highest-risk stations according to a rate based on residential population are all in places that are almost entirely nonresidential but which are major centres of day-to-day activity that are likely to provide many opportunities for crime. For example, Heathrow Terminals 123 is the main Underground station for one of the world's busiest international airports, but only 460 people live in output areas captured by the 960-metre buffer around the station. Since the residential-population denominator is very small in this case, the resulting crime rate appears very high. Residential population is likely to be equally problematic as a basis for calculating crime rates on other transport systems that serve commercial airports or other centres of activity, such as large out-of-town shopping malls.

The five stations with the highest risk when calculated using workday population are all on the same Underground line in a single area of London. This may demonstrate the limits of using data from decennial 
censuses that cannot reflect changes in areas between surveys. The Jubilee Line Extension project, together with the 2012 Olympics, spurred substantial regeneration in this part of London (Evans, 2014 MejiaDorantes, 2014). Between the census in March 2011 and the end of 2014, the number of people working in Tower Hamlets borough, for example, increased by $20 \%$ (Office for National Statistics, 2014). The census data used to calculate the workday population in this area is therefore likely to have underestimated the number of people present, relative to other areas of London, and so made crime rates appear higher than they would otherwise be. Despite this limitation, the 2011 census remains the most recent source of workday population data for small geographical areas.

The two measures that appear to be most-similar to one another are the entry/exit measure and the entry/exit/interchange metrics: $84 \%$ of the lines in Figure 3 show the same risk for both measures because those stations do not offer the opportunity for interchange. The exception is stations at which relatively few passengers start or end their journeys but which are major interchange points. Acton Town, for example, serves a medium-density residential area but is also a well-used interchange between two busy Underground lines. Of the seven stations that have entry/exit rates more than double their entry/exit/interchange rate, five (Finchley Road, Kennington, Mile End, Stockwell and West Ham) are important network interchanges in otherwise unremarkable residential areas.

One limitation of passenger-based rates for rare events such as violent crime is that at stations with few passengers, even a small number of crimes can produce a high crime rate. For example, the highest-risk station according to both passenger-based denominators is Roding Valley, the least-used station on the LU network, which was the site of only one violent crime in 2014. In such circumstances it may be more useful to group stations according to risk, rather than attempting to make fine distinctions between individual stations based on small numbers of crimes.

The example stations highlighted in Figure 3 suggest that there may be groups of stations that are similar with respect to violent crime counts and rates. Figure 4 shows the stations in each of the four clusters produced by the PAM algorithm. Each panel in the figure shows every LU station, with the stations in that cluster represented by black lines. Clusters 1 and 3 represent crime-neutral areas. Both have low crime counts and rates, differing only in that Cluster 1 represents the more-extreme cases. Cluster 2 appears to represent crime generators: stations with high crime counts but low crime rates. Conversely, Cluster 4 appears to represent crime enablers: places with few crimes but high crime rates. Based on this analysis there do not appear to be any stations that would be considered crime attractors (places with high counts and high rates). 
Figure 4: Distribution of violent crime rates for 2014 for clusters of stations produced by the PAM algorithm.

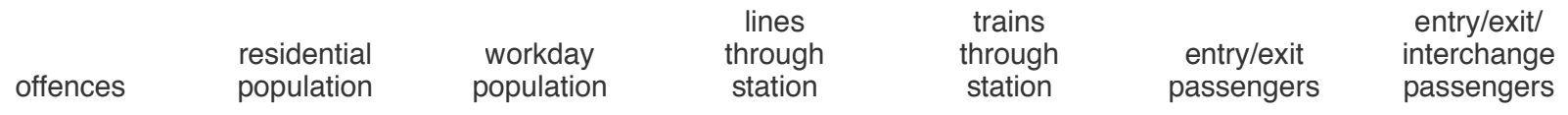

Cluster 1: almost no crime $\left(n=88, \bar{s}_{1}=0.64\right)$

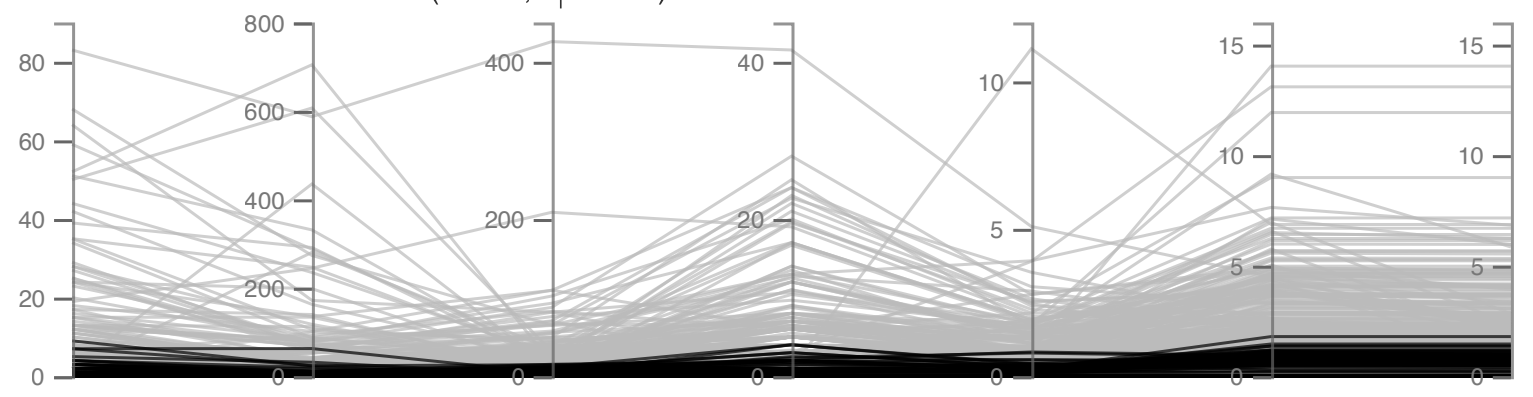

Cluster 2: high count, low rate $\left(n=18, \bar{s}_{2}=0.22\right)$

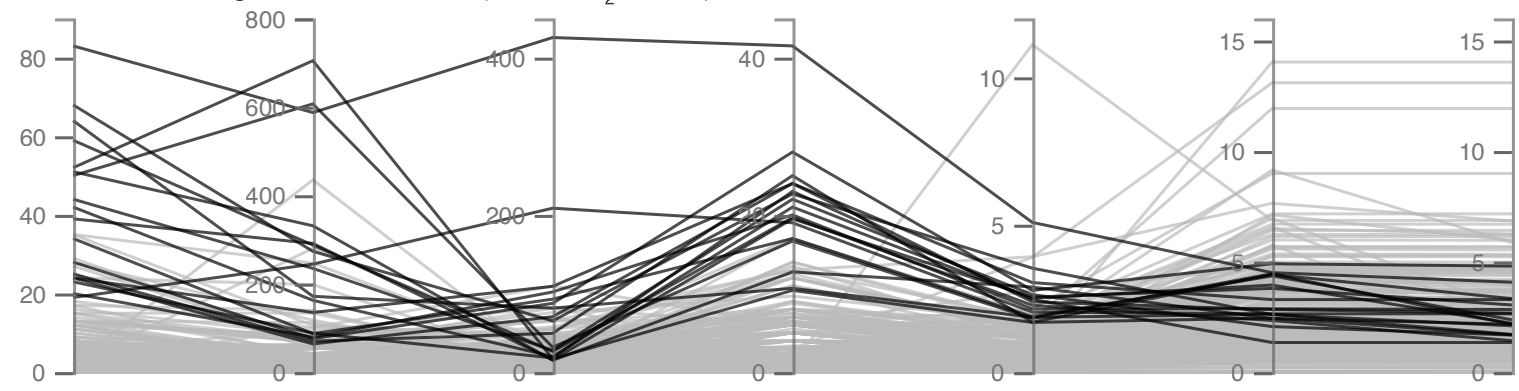

Cluster 3: low count, low rate $\left(n=117, \bar{s}_{3}=0.27\right)$

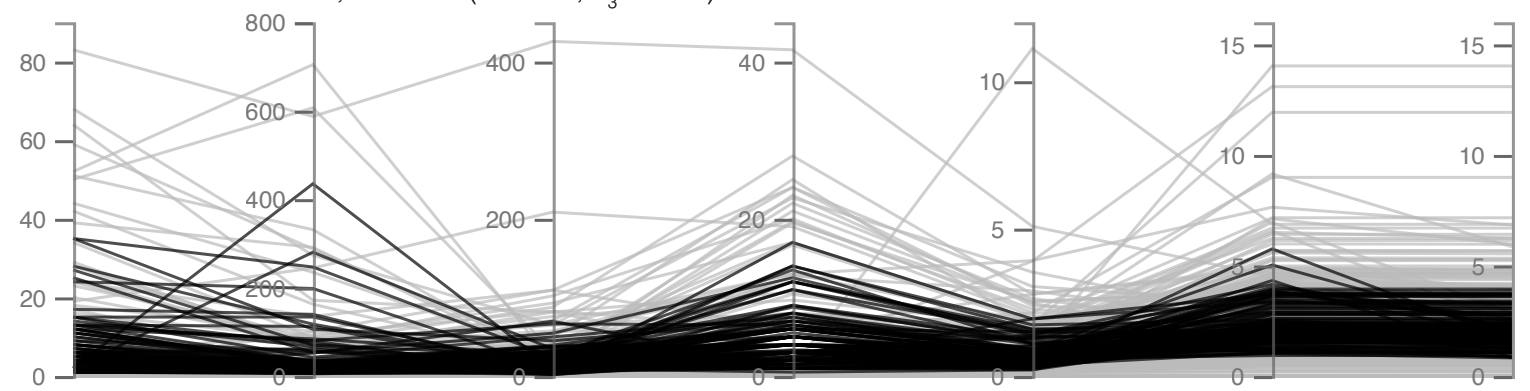

Cluster 4: low count, high rate $\left(n=45, \bar{s}_{4}=0.22\right)$

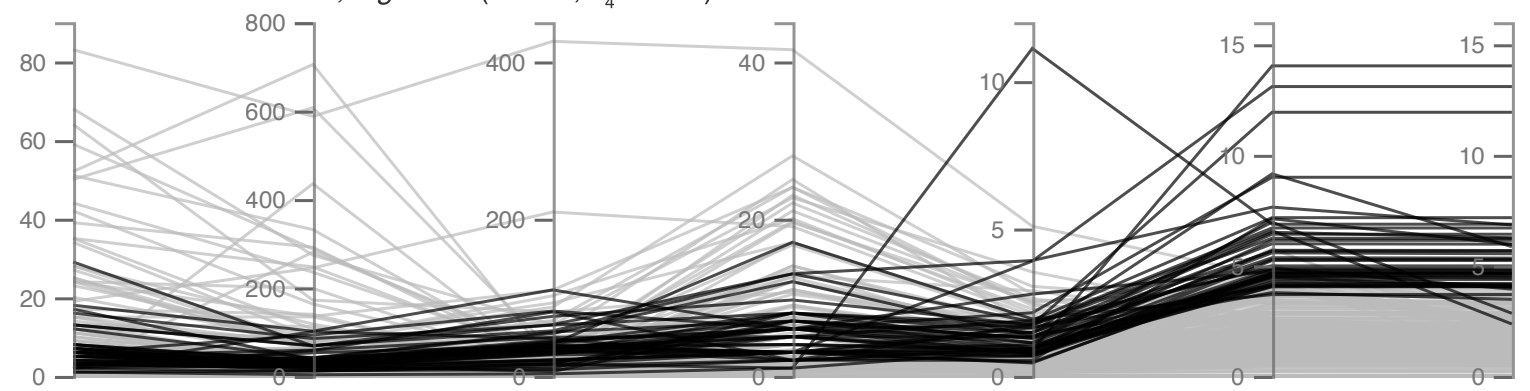

Powered by TfL Open Data 
The validity of the clusters produced by the PAM algorithm can be assessed by a statistic referred to as the average silhouette or $\bar{s}$ (Rousseeuw, 1987). Values of $\bar{s}$ approaching one indicate that the PAM process has produced tight clusters that are clearly distinguished from one another. Conversely, values of $\bar{s}$ close to zero suggest many stations are positioned between cluster centroids.

Overall, for the clusters shown in Figure $4, \bar{s}=0.38$. This suggests that while the clusters have a clear structure, there is overlap between them. Considering the clusters individually, Cluster 1 has a substantially stronger structure $\left(\bar{s}_{1}=0.64\right)$ than the other clusters $\left(\bar{s}_{2}=0.22, \bar{s}_{3}=0.27, \bar{s}_{4}=0.22\right)$. It should be expected that there should be some residual variance after the clustering, since the clusters are based solely on the crime count and rates at each station, rather than detailed information on the individual station characteristics. Nevertheless, the presence of clusters that match the classification of crime places outlined by Clarke and Eck (2003) suggests that classification has some validity for identifying different crime place characteristics of different stations.

The clusters can also be understood using the concepts of availability and accuracy discussed earlier. The denominators for which data are most likely to be available (shown towards the left-hand side of Figures 3 and 4 produce rates that closely mirror crime counts. For example, almost all the stations with high rates based on residential population are in the cluster dominated by stations with high crime counts. This can also be seen in the high value of $\tau$ for those denominators (Figure 3). These denominators are easily available, but do not accurately represent the availability of opportunities for crime. Conversely, the denominators that are less likely to be available (on the right-hand side of Figures 3 and 4 ) appear to be more representative of individual risk.

Maps showing crime risk on LU according to each denominator, along with the data used to calculate each rate and the cluster to which each station was allocated, are available as supplementary material attached to the online version of this article.

\section{Conclusion}

This study sought to understand how the choice of denominator can influence crime rates on public transport systems, how those considerations were different from those for non-transport crime, and how those differences might influence analysis based on crime rates.

The results of variation in at risk stations between denominators presented here demonstrate that denominator choice can have a substantial impact on calculations of crime rates and the extent to which those rates provide an accurate picture of crime risk, defined as crimes per opportunity for a crime to occur. In 
considering the common analytical question of where to allocate resources, Table 1 shows that denominator choice can have a substantial impact on analytical conclusions.

It is also clear that denominators which may be appropriate for non-transport crime cannot be safely used for transport crime. Transport systems sit within the surrounding environment and are influenced by it, but are also distinct from it and influenced by different factors. This can be seen in the influence of using denominators that include passengers transferring between trains on the crime rates at stations that are important transport interchanges.

Calculating crime rates for public transport systems presents particular challenges, but may also be easier in some respects than calculating rates for street crime. Transport systems typically have a single operator or regulator with an interest in understanding flows of people through the system. Such organisations may be more likely to commission surveys or other exercises to monitor the flow of people - obtaining such data for street crime is rare, as mentioned in the introduction. There are likely to still be transport systems, however, where such information is not available.

Analysts calculating rates for transport crime should use the available data that best represents the opportunities for a particular type of crime to occur in a particular environment. What this denominator is will depend not only on the availability of data but on the type of crime. For violent crime the best denominator is likely to be the number of passengers in an area (presented in Figure 5), but for other types of crime other denominators will be required. For on-train graffiti, for example, it may be the number of trains in an area. For theft of track-side copper cable, it may be the number of kilometres of track around each station. For staff assaults, it may be the number of person-hours worked by staff at each station. Whatever denominator is chosen, the stark differences in results caused by changing denominators in this study shows the importance of making a choice with care.

Finally the variation of stations between high count and risk denominators allows for the grouping of stations into different crime places. By being able to categorise stations in this way, analysts can develop strategic problem solving approaches to target various stations, and differentiate between the possible reasons for a station appearing as high crime or high risk as a result of their analysis.

\section{Supplementary material}

Maps and tables showing the stations with the highest apparent risk based on each denominator are available as supplementary material attached to the online version of this article. The data used in this study - including denominator values for each station and the associated crime rates - are available at 
Figure 5: Rate of violent crimes recorded by police as occurring at each London Underground station per 10,000 passengers entering, exiting or interchanging at the station each day, 2014. The five stations with the highest rates are labelled.

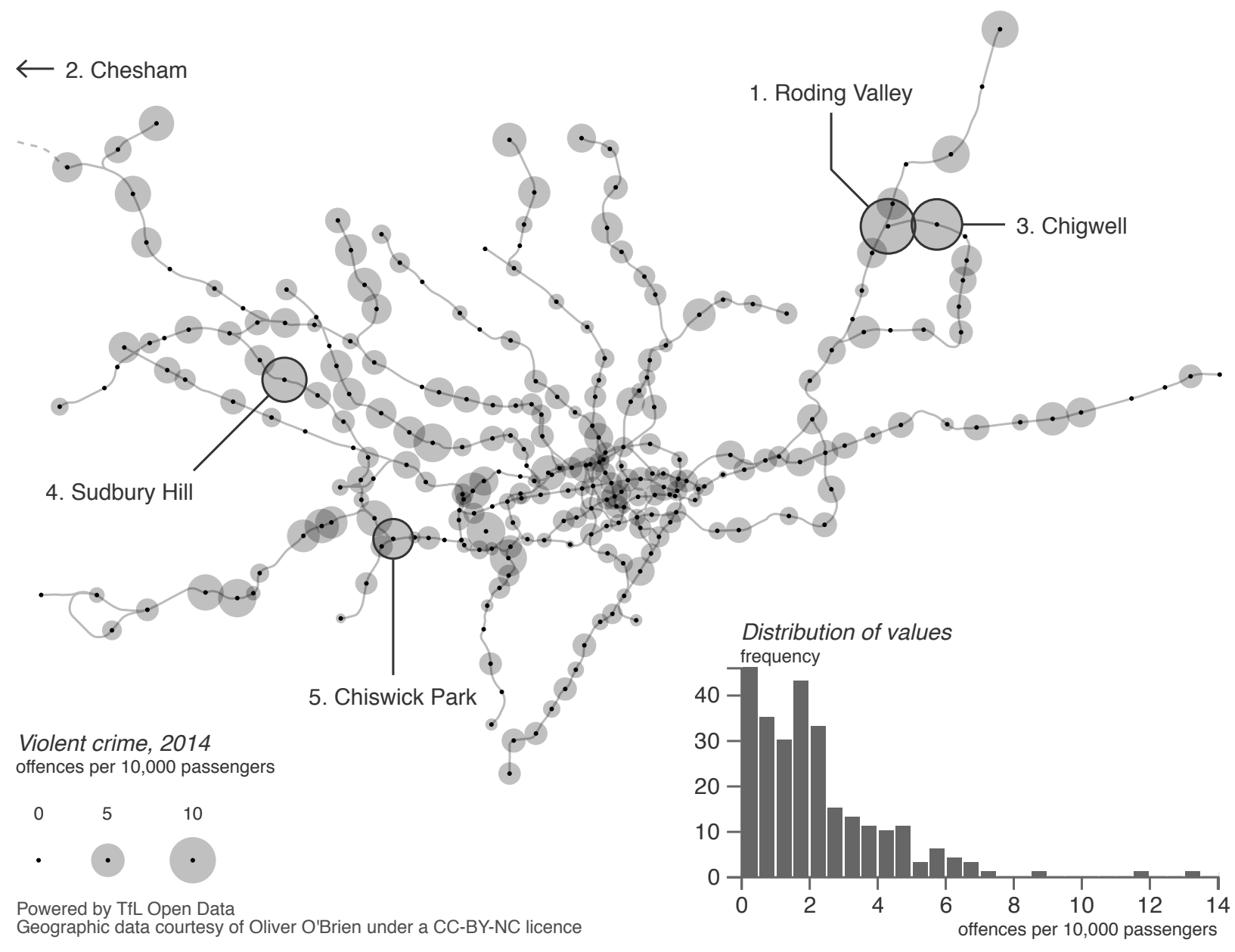

http://doi.org/10.17605/0SF.IO/5QV38

\section{Acknowledgments}

This research was facilitated by the UCL Centre for Transport Studies. Early versions of this article were presented to the Transport Statistics User Group, Transport for London and at the Stockholm Criminology Symposium. The authors wish to thank those who contributed to the discussions at these events, which helped to improve this research.

The census, crime and ridership open data used in this study contain public sector information licensed under the UK Open Government Licence. 


\section{References}

M A Andresen. Diurnal movements and the ambient population: An application to municipal-level crime rate calculations. Canadian Journal of Criminology and Criminal Justice, 52(1):97-107, 2010. doi: 10.3138/cjccj.52.1.

M A Andresen, G W Jenion, and A A Reid. An evaluation of ambient population estimates for use in crime analysis. Crime Mapping: A Journal of Research and Practice, 4(1):7-30, 2012.

M P J Ashby and K J Bowers. Concentrations of railway metal theft and the locations of scrap-metal dealers. Applied Geography, 63:283-291, 2015. doi: 10.1016/j.apgeog.2015.07.005.

Association of Chief Police Officers. Practice Advice on Analysis. National Policing Improvement Agency, Wyboston, 2008.

S L Boggs. Urban crime patterns. American Sociological Review, 30(6):899-908, 1965.

A Braga, A Papachristos, and D Hureau. The effects of hot spots policing on crime: an updated systematic review and meta-analysis. Justice Quarterly, 31(4):633-663, 2014. doi: 10.4073/csr.2012.8.

P J Brantingham and P L Brantingham. Environmental Criminology. Sage, Beverly Hills, CA, 1981.

P L Brantingham and P J Brantingham. Criminality of place. European Journal on Criminal Policy and Research, 3(3):5-26, September 1995. doi: 10.1007/BF02242925.

R Cervero and A Golub. Informal transport: A global perspective. Transport Policy, 14(6):445-457, 2007. doi: 10.1016/j. tranpol.2007.04.011.

S Chainey and J Desyllas. Modelling pedestrian movement to measure on-street crime risk. In M Wachowicz, editor, MovementAware Applications for Sustainable Mobility: Technologies and Approaches: Technologies and Approaches, pages 243-263. IGI Global, 2010. doi: 10.4018/978-1-61520-769-5.ch015.

R V Clarke and J E Eck. Become a Problem Solving Crime Analyst in 55 Small Steps. Jill Dando Institute of Crime Science, London, 2003.

L E Cohen and M Felson. Social change and crime rate trends: a routine activity approach. American Sociological Review, 44 (4):588-608, 1979.

L E Cohen, R L Kaufman, and M R Gottfredson. Risk-based crime statistics: a forecasting comparison for burglary and auto theft. Journal of Criminal Justice, 13(5):445-457, 1985. doi: 10.1016/0047-2352(85)90044-3.

Department for Homeland Security. Transportation Systems Sector-Specific Plan. Department for Homeland Security, Washington, DC, 2015.

J E Eck. Preventing crime at places. In L W Sherman, D P Farrington, B C Welsh, and D L MacKenzie, editors, Evidence-Based Crime Prevention, chapter 7. Routledge, London, 2002.

J E Eck and T D Madensen. Meaningfully and artfully reinterpreting crime for useful science: an essay on the value of building with simple theory. In M A Andresen and G Farrell, editors, The Criminal Act: the role and influence of routine activity theory, chapter 2, pages 5-18. Palgrave Macmillan, Basingstoke, Hampshire, 2015. doi: 10.1057/9781137391322.0006.

G Evans. London 2012 and regional regeneration: Legacy games. Regions, 295:11-13, 2014. doi: 10.1080/13673882.2014. 11006051.

E R Groff. Simulation for theory testing and experimentation: An example using routine activity theory and street robbery. Journal of Quantitative Criminology, 23(2):75-103, 2007. doi: 10.1007/s10940-006-9021-z.

K D Harries. Alternative denominators in conventional crime rates. In P J Brantingham and P L Brantingham, editors, Environmental Criminology, chapter 8, pages 147-165. Sage, Beverly Hills, 1981. 
J B Kinney, P L Brantingham, K Wuschke, M G Kirk, and P J Brantingham. Crime attractors, generators and detractors: Land use and urban crime opportunities. Built Environment, 34(1):62-74, apr 2008. doi: 10.2148/benv.34.1.62.

J Kurland, N Tilley, and S D Johnson. The football 'hotspot' matrix. In Football Hooliganism, Fan Behaviour and Crime, pages 21-48. Springer, 2014.

A M Lemieux and M Felson. Risk of violent crime victimization during major daily activities. Violence and victims, 27(5): $635-655,2012$.

S Lottier. Distribution of criminal offenses in sectional regions. Journal of Criminal Law and Criminology, 29(3):329-344, 1938. doi: $10.2307 / 1137820$.

M Maechler, P Rousseeuw, A Struyf, M Hubert, and K Hornik. cluster: Cluster Analysis Basics and Extensions, 2016. URL https://cran.r-project.org/web/packages/cluster//

$\mathrm{N}$ Malleson and M A Andresen. The impact of using social media data in crime rate calculations: shifting hot spots and changing spatial patterns. Cartography and Geographic Information Science, 42(2):112-121, 2015.

K Mejia-Dorantes, Lucas. Public transport investment and local regeneration: A comparison of London's Jubilee Line Extension and the Madrid Metrosur. Transport Policy, 35:241-252, 2014. doi: 10.1016/j.tranpol.2014.05.020.

A D Newton, H Partridge, and A Gill. Above and below: measuring crime risk in and around underground mass transit systems. Crime Science, 3(1), 2014a. doi: 10.1186/2193-7680-3-1.

A D Newton, H Partridge, and A Gill. In and around: Identifying predictors of theft within and near to major mass underground transit systems. Security Journal, 27(2):132-146, 2014b. doi: 10.1057/sj.2014.2.

Office for National Statistics. 2011 Census: The workday population of England and Wales - an alternative 2011 Census output base, 2013. URL https://www.ons.gov.uk/peoplepopulationandcommunity/populationandmigration/ populationestimates/articles/theworkdaypopulationofenglandandwales/2013-10-31

Office for National Statistics. Regional labour market, december 2014, 2014. URL http://www.ons.gov.uk/ons/rel/ subnational-labour/regional-labour-market-statistics/december-2014/

Office for National Statistics. 2011 Census aggregate data. UK Data Service, London, June 2016 edition, 2016. doi: 10.5257/ census/aggregate-2011-1.

Office for National Statistics. Census geography, 2017. URL https://www.ons.gov.uk/methodology/geography/ ukgeographies/censusgeography

Open Knowledge Foundation. Open definition version 2.1, 2017. URL http://opendefinition.org/od/2.1/en/

M D Peck. Barriers to Using Fixed-Route Public Transit for Older Adults. Mineta Transportation Institute, San José, CA, 2010.

J S Perone. Advantages and Disadvantages of Fare-Free Transit Policy. National Center for Transportation Research, Tampa, FL, 2002.

L E Pettiway. Measures of opportunity and the calculation of the arson rate: The connection between operationalization and association. Journal of Quantitative Criminology, 1(3):241-268, 1985.

R Core Team. R: A Language and Environment for Statistical Computing. R Foundation for Statistical Computing, Vienna, Austria, 2014. URL http://www.R-project.org/

J H Ratcliffe. Crime mapping: Spatial and temporal challenges. In A R Piquero and D Weisburd, editors, Handbook of Quantitative Criminology, chapter 2, pages 5-24. Springer, New York, 2010.

K Ray, R Davidson, F Husain, S Vegeris, K Vowden, and J Karn. Perceptions of the policing and crime mapping 'Trailblazers'. 
Number 67 in Home Office Research Report series. Home Office, London, October 2012.

G F Rengert. Burglary in Philadelphia: a critique of an opportunity structure model. In P J Brantingham and P L Brantingham, editors, Environmental Criminology, chapter 10, pages 189-201. Sage, Beverly Hills, CA, 1981.

C Rodier and E Issac. Transit Performance Measures in California. Number 12-58 in MTI Reports series. Mineta Transportation Institute, San José, CA, 2016.

E Rodríguez-Núñez and J C García-Palomares. Measuring the vulnerability of public transport networks. Journal of Transport Geography, 35:50-63, 2014. doi: 10.1016/j.jtrangeo.2014.01.008.

P J Rousseeuw. Silhouettes: a graphical aid to the interpretation and validation of cluster analysis. Journal of Computational and Applied Mathematics, 20:53-65, 1987. doi: 10.1016/0377-0427(87)90125-7.

W G Skogan. Citizen reporting of crime: Some national panel data. Criminology, 13(4):535-549, 1976.

M J Smith and R V Clarke. Crime and public transport. Crime and Justice, 27:169-233, 2000.

Steer Davies Gleave. Estimates of Station Usage 2015-16 - Methodological Report. Steer Davies Gleave, London, 2017.

B Stipak. Alternatives to population-based crime rates. International Journal of Comparative and Applied Criminal Justice, 12(2):247-260, 1988. doi: 10.1080/01924036.1988.9688896.

K Teschke, M A Harris, C C O Reynolds, H Shen, P A Cripton, and M Winters. Exposure-based traffic crash injury rates by mode of travel in British Columbia. Canadian Journal of Public Health/Revue Canadienne de Santé Publique, 104(1): e75-e79, 2013. doi: canajpublheal.104.1.0e75.

L Tompson, S D Johnson, M P J Ashby, C Perkins, and P Edwards. UK open source crime data: accuracy and possibilities for research. Cartography and Geographic Information Science, 42(2):97-111, 2014. doi: 10.1080/15230406.2014.972456.

Transport for London. TfL Rolling Origin and Destination Survey, 2014. URL https://data.london.gov.uk/dataset/ tfl-rolling-origin-and-destination-survey.

Transport for London. Assessing Transport Connectivity in London. Transport for London, London, 2015a. URL http: //content.tfl.gov.uk/connectivity-assessment-guide.pdf

Transport for London. Travel in London. Transport for London, London, 2015b. URL http://content.tfl.gov.uk/ travel-in-london-report-8.pdf

Transport for London. Underground services performance, 2017. URL https://tfl.gov.uk/corporate/ publications-and-reports/underground-services-performance

D L Weisburd. The law of crime concentration and the criminology of place. Criminology, 53(2):133-157, 2015.

A F Williams. Teenage drivers: patterns of risk. Journal of Safety Research, 34(1):5-15, 2003. doi: 10.1016/S0022-4375(02) 00075-0. 